Acta Histochem. Cytochem. 32 (6): 465-476, 1999

\title{
Extinction of Organelles in Differentiating Epidermis
}

\author{
Kiyokazu Morioka1, Hiromi Takano-Ohmuro², Masasumi Sameshima ${ }^{3}$, Takashi Ueno ${ }^{4}$, \\ Eiki Kominami ${ }^{4}$, Hitoshi Sakuraba ${ }^{1}$ and Setsunosuke Ihara ${ }^{5}$ \\ 'Department of Clinical Genetics, ${ }^{2}$ Department of Pharmacology, Faculty of Medicine, University of Tokyo, 7-3-1 \\ Hongo, Bunkyo-ku, Tokyo 113-0033, ${ }^{3}$ Department of Cell Biology, The Tokyo Metropolitan Institute of \\ Medical Science, 3-18-22 Honkomagome, Bunkyo-ku, Tokyo 113-8613, 4 Department of Biochemistry, \\ Juntendo University School of Medicine, 2-1-1 Hongo, Bunkyo-ku, Tokyo 113-8421 and Department \\ of Biological Science, Faculty of Life and Environmental Science, Shimane University, 1060 \\ Nishikawazu-cho, Matsue-City, Shimane 690-8504
}

Received September 6, 1999; accepted December 20, 1999

\begin{abstract}
In the dorsal skin of fetal rats, the epidermis on day 16 of gestation consisted of a single or a few layers of undifferentiated cells, and it developed to display the full strata, i.e. the stratum (s.) corneum (horny layer), s. granulosum (granular layer), s. spinosum (spinous layer), and s. germinativum (basal layer) by the day of birth. Perinuclear electron lucent special areas, which were also detectable by conventional staining under light microscope, appeared in the cells of the s. spinosum or the s. granulosum on the day of birth. We call such an area the "perinuclear compartment (PNC)". The PNC was not partitioned by membranous structures either. Typical PNCs became recognizable on the day of birth. The cell nuclei seemed to be digested inside of the PNC of the cells

located in the outermost area of the $s$. granulosum or sometimes in the boundary between the s. granulosum and the s. corneum. In the initial phase of nuclear extinction, morphology of the nucleus undergoing degeneration resembles that of apoptotic cells. In comparison to the morphological degeneration of the nucleus, DNA fragmentation was suggested to occur earlier. Localization of cathepsin B and cathepsin D in the s. spinosum and $\mathbf{s}$. granulosum as revealed by immunohistochemistry, together with an electron microscopic study on the appearance of autophagosomes in those areas, suggested a contribution of autophagy to the digestion of organelles including mitochondria and endoplasmic reticula in the terminal differentiation of epidermal cells.
\end{abstract}

Key words: Keratinocyte, Lysosome, Programmed cell death, Cathepsin, Rat

\section{Introduction}

Epidermis serves as an elegant model for studying the cellular differentiation process in vivo $[9,33]$ or in vitro $[11,15]$, since its constituent cells are arranged in order according to the stages of differentiation. Fetal epidermis starts to differentiate simultaneously and the epidermis at the period around the birth consists of keratinocytes almost exclusively. Furthermore it shows the process of differentiation clearer in detail than that of adult tissues. Epidermal cells lose their organelles including mitochondria, endoplasmic reticula and nuclei in the process of keratinization, while the mechanisms responsible for the disappearance of these organelles have not been fully

Correspondence to: Dr. Kiyokazu Morioka, Department of Clinical Genetics, The Tokyo Metropolitan Institute of Medical Science, 3-18-22 Honkomagome, Bunkyo-ku, Tokyo 113-8613, Japan. elucidated. In this paper, we have studied the morphology of keratinocytes with special interest on the mechanisms of the extinction of organelles. It is known that the degeneration of nuclei is accompanied by DNA fragmentation [25, 29, 45]. Although morphological similarity to apoptotic cells has been pointed out to be one of the features of differentiating keratinocytes $[31,43,50]$, we have studied the structure of nuclei and cytoplasm in detail during the terminal differentiation of fetal and neonatal keratinocytes, and have shown that the programmed cell death (PCD) in these cells occurs in a keratinocytespecific manner as well as displaying apoptotic aspects.

According to the most widely accepted manner of classification, cell death is divided into two forms, one is necrosis and the other is apoptosis [51], and the latter is often considered to be identical to programmed (physiological) cell death (PCD) $[1,18]$. However, other types of the classification are possible. For example, Schweichel 
and Merker [39] divided PCD into 3 types based on the condensation of the nucleus and the cytoplasm and the contribution of the lysosomal system. Their idea was extended and refined by Clarke [5], who classified PCD into three morphological types: "apoptotic", "autophagic", and "non-lysosomal vesicular". The destruction of the cytoplasm in these three types of processes appears to be achieved primarily by heterophagy, by autophagy and by non-lysosomal degradation, respectively.

Among several types of cells in which PCD is known to occur, epidermal cells, hair follicle cells, erythrocytes and eye lens cells etc. have special features that they lose almost all of their organelles before death. We focused on autophagy to explain the extinction of organelles. Autophagy may participate in the terminal differentiation process of the epidermis in a delicate way, because the cells must remain functional after the disappearance of their organelles. In other words, the typical rapid cell death seen in the case of apoptosis must be avoided. One of the purposes of this study was to estimate the contribution of autophagy to the terminal differentiation process. We therefore examined the morphological features of the lysosomal systems of the epidermis by electron microscopy as well as by immunohistochemistry.

\section{Materials and Methods}

\section{Materials}

Sprague-Dawley rats were purchased from Nippon SLC Inc. (Hamamatsu, Japan). The day on which sperm could be detected in the vagina was taken as day 0 of gestation. Anti-human cathepsin D monoclonal antibody (C47620) was purchased from Transduction Laboratories Inc. (Lexington, KY). Anti-human cathepsin B rabbit antibody was prepared as described previously [22]. Anti-rat lysosomal glycoprotein lgp 120 rabbit antibody was prepared as described previously (Lewis et al. 1985). Anti-porcine vimentin monoclonal antibody (RPN1102) was purchased from Amersham-Pharmacia Ltd. (Little Chalfont, UK).

\section{Electron microscopy}

Pieces of dorsal skin of fetal and neonatal animals were obtained by means of a dermal punch. They were fixed overnight in a solution of $3.7 \%$ paraformaldehyde and $1 \%$ glutaraldehyde in $50 \mathrm{mM}$ Na-phosphate buffer (pH 7.2) at $4^{\circ} \mathrm{C}$. The fixed tissue blocks were washed thoroughly in PBS (saline in $10 \mathrm{mM}$ Na-phosphate buffer, $\mathrm{pH} 7.2$ ), and were treated with $2 \%$ osmium tetroxide in PBS for $1 \mathrm{hr}$ at $4^{\circ} \mathrm{C}$. After washing 4 times with PBS, the blocks were passed through a series of alcohol dehydration steps and propylene oxide permeation steps, and they were then embedded in EPON (Poly/Bed 812; Polysciences Inc., Warrington, PA). Ultrathin sections (approx. $80 \mathrm{~nm}$ in thickness) were cut and stained with $4 \%$ uranyl acetate in $50 \%$ ethanol followed by staining with lead citrate. The observations were performed using a JEM
1010 electron microscope (JOEL Ltd., Tokyo, Japan).

\section{Immunoblotting}

The tissue block was solubilized by sonication in $5 \%$ SDS, 5\% 2-mercaptoethanol, $0.2 \mathrm{mM}$ phenylmethylsulfonyl fluoride, $0.1 \mathrm{mM}$ di-isopropyl fluorophosphate, $28 \mu \mathrm{M}$ L-1-tosylamide-2-phenylethylchloromethyl ketone, $0.2 \mathrm{mM}$ EGTA and $0.1 \mathrm{M}$ Tris-HCl $(\mathrm{pH}$ 6.8), followed by a heat treatment in a boiling water bath for $3 \mathrm{~min}$. The solubilized proteins were subjected to SDS-polyacrylamide gel electrophoresis in 3-18\% gradient gel [46]. The separated proteins were transferred to nitrocellulose membrane. The blotted membrane was soaked in $5 \%$ non-fat milk for $60 \mathrm{~min}$, and probed with antibodies for $60 \mathrm{~min}$ at room temperature. Then alkaline phosphatase-conjugated anti-mouse IgG or anti-rabbit IgG was applied. The membrane was washed with a solution containing $20 \mathrm{mM}$ Tris- $\mathrm{HCl}(\mathrm{pH} 7.5), 0.15 \mathrm{M} \mathrm{NaCl}, 0.05 \%$ Tween 20 for a total of $20 \mathrm{~min}$, changing the solution every $5 \mathrm{~min}$. The antigen was detected by incubation in a solution containing BCIP and NBT according to the manufacturer's (Promega, Madison, WI) instructions.

\section{Immunohistochemistry}

Pieces of dorsal skin tissue of fetal and neonatal rats were fixed with $10 \%$ formalin neutral buffer and stored as paraffin wax embedded blocks. As the need arose, they were cut into sections each $4 \mu \mathrm{m}$ in thickness and these were used for the photomicroscopical and immunohistochemical studies.

After deparaffinization, the sections were rehydrated and washed several times with PBS. To diminish endogenous peroxidases, they were incubated with $0.3 \%$ hydrogen peroxide in methanol for $30 \mathrm{~min}$ followed by brief washing with distilled water and subsequently with PBS. The sections were incubated for $10 \mathrm{~min}$ in PBS containing 5\% normal horse serum, and were then reacted with diluted solution of the primary antibody (dilutions were $1: 50-1: 100$ for monoclonal antibodies and $1: 200$ 1:400 for polyclonal antibodies) for $16 \mathrm{hr}$ at $4^{\circ} \mathrm{C}$. Control sections were incubated with $5 \%$ horse serum without the primary antibody. Then they were washed three times (10 min each) with PBS and incubated in a solution (dilution $1: 200$ or $1: 400$ ) of biotin-conjugated IgG (Vector Laboratories Inc., Burlingame, CA). After three 10 min washes in PBS, the sections were incubated with streptoavidin/peroxidase preformed complex (Vector Laboratories Inc.) for $30 \mathrm{~min}$. The reaction was visualized by incubation in PBS containing $0.03 \%$ 3,3'diaminobenzidine and $0.3 \%$ hydrogen peroxide. Thereafter, the nuclei were stained with methylgreen-pyronine. Photographs of the stained cells were taken with an Optiphot-2 plus HFX-DX microscope system (Nikon Corp., Tokyo, Japan).

\section{In situ end-labeling of DNA strand breaks method}

The tissue sections were prepared in the same way as 
described in the histochemistry section. Then they were processed according to the manufacturer's manual by use of TACS 2 TdT (DAB) in situ apoptosis detection kit, which is a product of Trevigen, Inc. Gaithersburg, MD. In brief, rehydrated sections were treated with proteinase $\mathrm{K}(1 \mathrm{mg} / \mathrm{ml})$ for $10 \mathrm{~min}$ at room temperature, and then endogenous peroxidase was removed. End-labeling of DNA strand breaks were performed by terminal deoxynucleotidyl transferase in combination with biotinylated nucleotides, which was detected by streptoavidin-horseradish peroxidase conjugates. Diaminobenzidine was reacted with the above-tieated sections to generate an insoluble colored substrate where DNA fragmentation had occurred.

\section{Results}

\section{Development of epidermis}

Some textbooks include photographs of conventional paraffin sections of the skin of the human adult [33] or mouse embryo [41]. These show epidermal cells that have a vacuole-like structure around their nuclei. We reinvestigated the sections of developing rat skin to determine when the vacuole-like structure appears in the epidermis (Fig. 1). In the case of the fetal rats examined in the present study, day 16 epidermis was composed of a few layers of primitive keratinocytes and the peridermal layer (Fig. 1A). Day 18 epidermis already exhibited special features in that basal and peridermal cells were stained normally, whereas other intermediate cells seemed to have areas stained very poorly (Fig. 1B). By the day of birth, the poorly stained area was located around the nucleus (Fig. 1C, D). We named this area the perinuclear (cytoplasmic) compartment $=$ "PNC". Some adult cells also have the PNC and electron micrographs of the area corresponding to the PNC have appeared in previous publications [31, 33], however, it has not yet been studied intensively.

The developmental process of epidermis was also studied by electron microscopy. In contrast to day 18 epidermis which has no layers corresponding to s. corneum (Fig. 2, [3]), day 20 epidermis contained several layers of s. corneum as well as s. granulosum, s. spinosum, and s. germinativum (Fig. 2A, B). These observations indicate that one layer of $\mathrm{s}$. corneum must be formed within half a day or a shorter period. The keratohyaline granules in the s. granulosum changed to the amorphous adult type and marked formation of tonofibrils was observed in the $s$. granulosum and the s. spinosum. Apoptotic morphology of the nucleus, which was not found on day 18 , appeared on day 20 (thick arrow in Fig. 2A). The heterochromatin was accumulated around the inner surface of the nucleus. Thus, adult-type morphological features of the epidermis were, for the most part, established by day 20 of gestation.

\section{Perinuclear compartment}

A special cytoplasmic area surrounding the nucleus, termed the "PNC", became apparent on day 20 of gestation. Although these areas may not have been electron lucent on day 20 (Fig. 2C), some became electron lucent on the day of birth (day 21 of gestation) (Fig. 3). The arrow in Fig. 3B indicates the PNC, which was clearly distin-
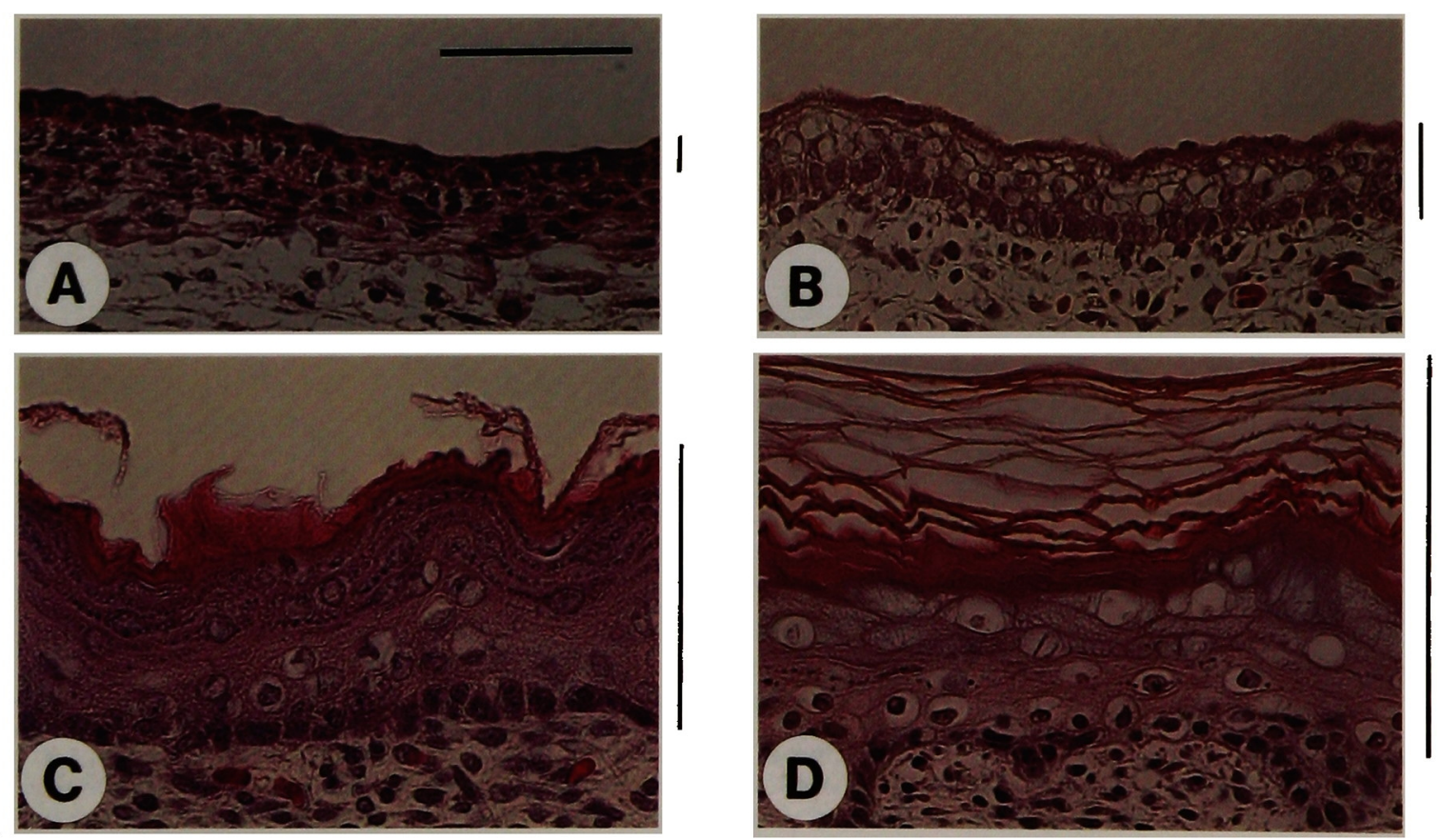

Fig. 1. Histological features of the skin of fetal rats on day 16 (A), day 18 (B), day 20 (C) of gestation and that of a neonatal rat on the day of birth (D). Horizontal bars represent $50 \mu \mathrm{m}$. Vertical bars represent the width of the epidermis. 

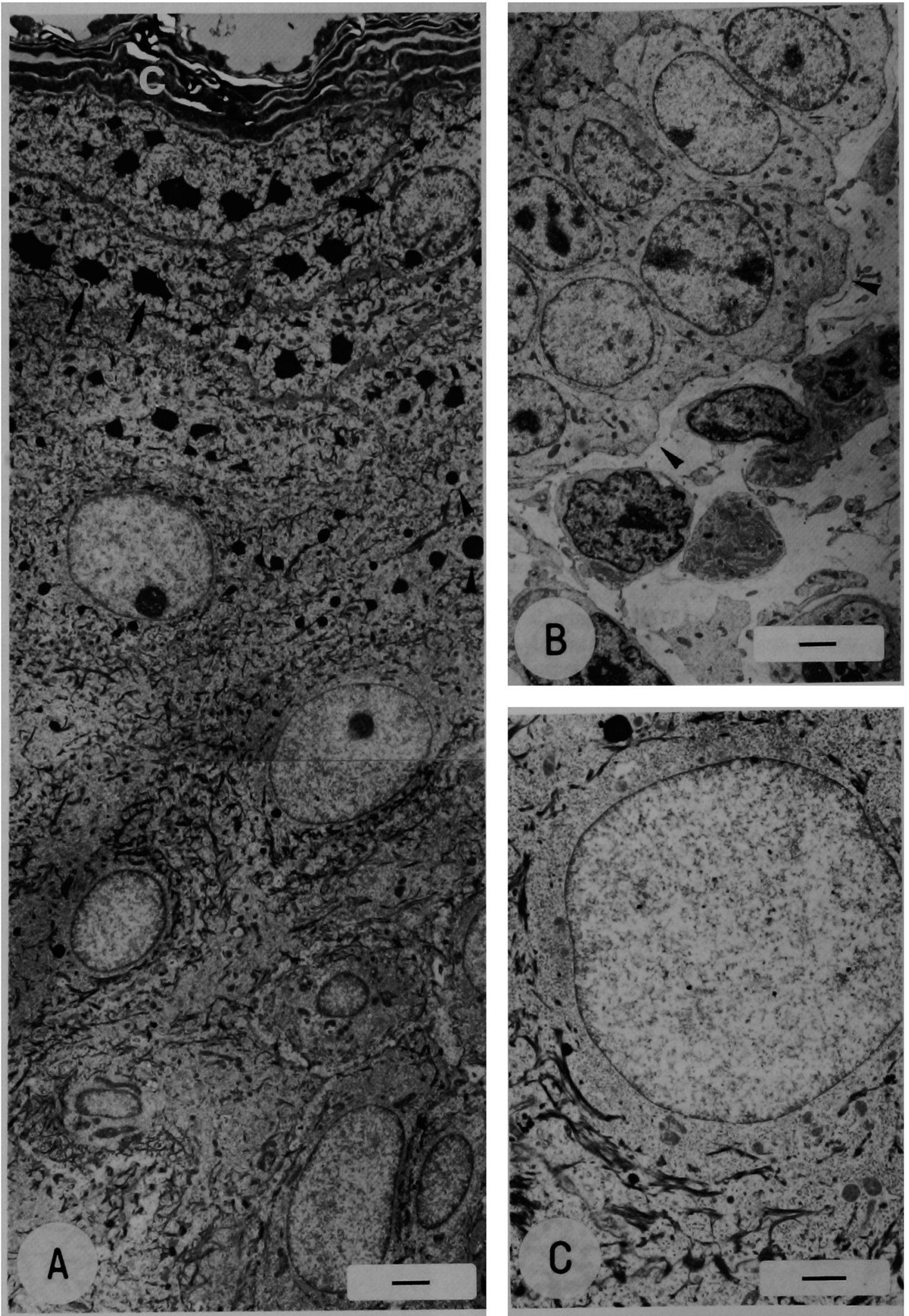

Fig. 2. Epidermis on day 20 of gestation. (A) Typical structure of the epidermis consisting of s. germinativum, s. spinosum, s. granulosum, and s. corneum was almost formed at this stage. Arrowheads and thin arrows indicate spherical and amorphous keratohyaline granules, respectively. Thick arrow indicates an apoptotic nucleus. A white $C$ denotes the s. corneum. Bar $=2 \mu \mathrm{m}$. (B) An area near the basement membrane (arrowheads). The upper left area represents the s. germinativum of the epidermis and the lower right represents the dermis. $\mathrm{Bar}=2 \mu \mathrm{m}$. (C) A structure near the nucleus of a cell in the s. spinosum. $B a r=1 \mu \mathrm{m}$. 
guishable from the other part of the cytoplasm, appeared in cells located just above the $s$. germinativum. In contrast, the nuclei in cells of the s. germinativum were surrounded by electron dense cytoplasm (arrowheads in Fig. 3B). These observations indicate that formation of the PNC may be one of the early signs of keratinocytic differentiation. Although tonofibrils and keratohyaline granules were usually found to be absent in the PNC, mitochondria or endoplasmic reticulum were often included in the PNC (Fig. 3C).

\section{Morphological changes in the nucleus}

The process of terminal differentiation usually includes morphological changes in the cell nucleus. The nuclei in the cells of the s. spinosum exhibit obviously different morphology in terms of having a spherical shape and showing loss of heterochromatin as compared to those in the cells of the s. germinativum which have a cylindrical shape and which show an abundance of heterochromatins (Fig. 3). We present here electron micrographs showing the various types of nuclei in cells located at the uppermost border of the $s$. granulosum where drastic restructuring of cells would be executed (Figs. 4, 5), such as extinction of organelles, disassembly of keratohyaline granules, and formation of closely weaved keratin filaments. Specimens were obtained from day 20 fetuses (Fig. 4) and neonatal animals on the day of birth (Fig. 5).

Typical apoptotic morphologies, such as accumulation of chromatins to the inside surface of the nucleus (Figs. 4A, 5A) and amorphous structure of nucleus (Figs. $4 B$ and $5 B, C)$, was observed in the early stages of the process of degeneration of the nucleus, whereas the morphology in later stages appeared to be somewhat keratinocyte-specific (Figs. 4C and Fig. 5D, G). Although convolution of the nuclear membrane was observed, separation of the nucleus into several pieces was not found. Margination of chromatin around the inside rim of the nuclear membrane was observed, while the large crescentic cap which is characteristic of typical apoptosis was not found. When cells entered into the border between s. granulosum and s. corneum, the cells and their nuclei were compressed and form laterally extended structures (Figs. 4D and 5E, F). In addition, of course, the cells remained evident in the epidermis for several days after complete digestion of the nucleus. It is noted that the PNC did not decrease in size in response to the degeneration of the nucleus. The inside area of PNC (*a in Fig. 5F) is generally electron lucent as compared to the ordinary cytoplasm ( ${ }^{*} \mathrm{~b}$ in Fig. $\left.5 \mathrm{~F}\right)$.

\section{DNA fragmentation}

DNA fragmentation is one of the well-known markers of apoptosis [10, 51]. Morphological degeneration of the nucleus and chromatin, as mentioned above, was expected to involve the fragmentation of DNA. Furthermore, it is of interest to determine where and when the fragmentation occurs during epidermal differentiation. Results obtained by means of the conventional in situ DNA-end labeling assay [10] are shown in Fig. 6. Dense staining of cytoplasm seen around the boundary between the $s$. spinosum and the s. granulosum as well as in the basal layer may be a false positive DAB reaction [17]. The

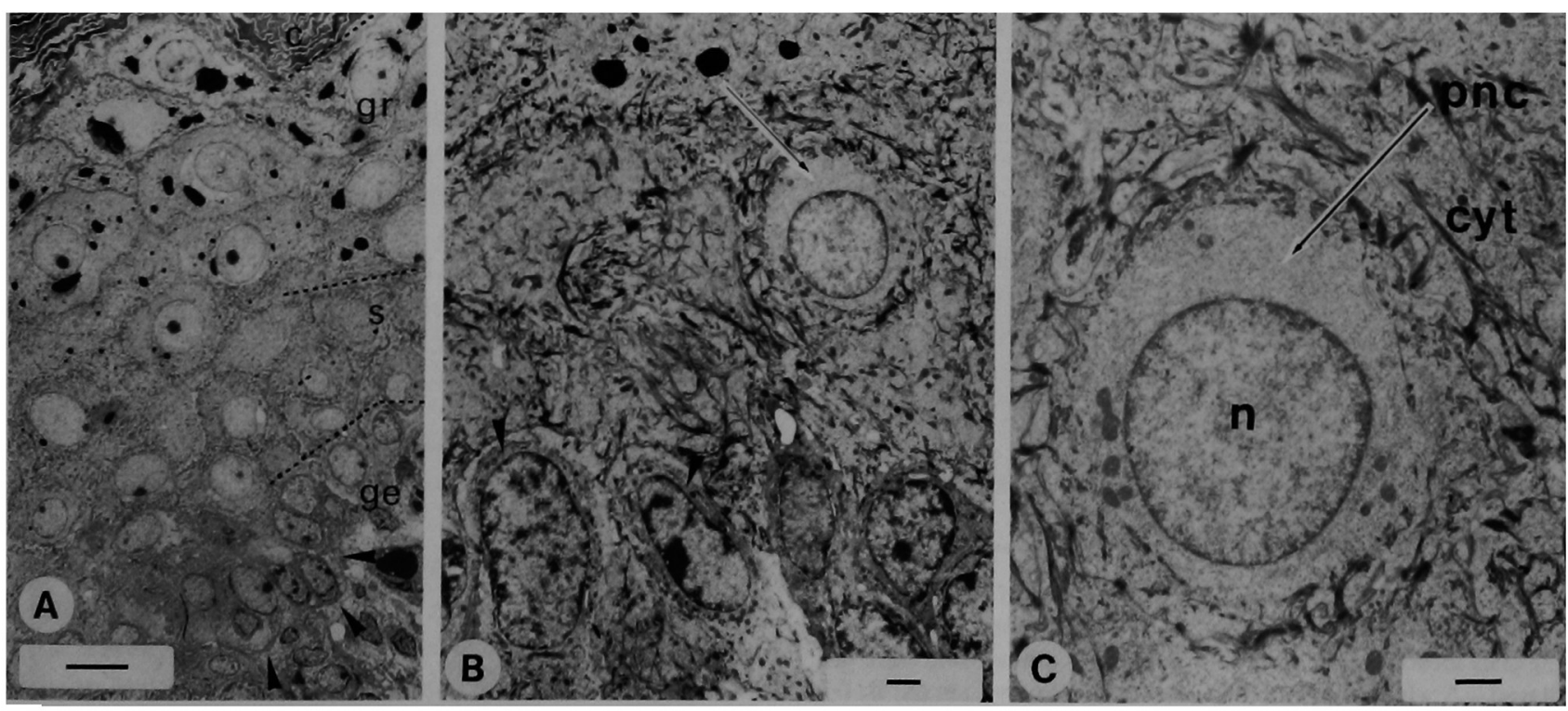

Fig. 3. Epidermis on the day of birth. (A) Whole view. ge, s. germinativum; s, s. spinosum; gr, s. granulosum; c, s. corneum. Arrowheads indicate the basal surface of epidermis. Bar $=10 \mu \mathrm{m}$. (B) In the cells of the s. germinativum the nucleus is surrounded by an electron dense area (arrowheads), whereas in the cells of the s. spinosum the nucleus is surrounded by the electron lucent area (arrow). Bar $=2 \mu \mathrm{m}$. (C) Enlarged view of (B). Electron lucent area that surrounds the nucleus was termed the perinuclear (cytoplasmic) compartment (pnc). cyt, normal cytoplasm; $\mathrm{n}$, nucleus. Bar $=1 \mu \mathrm{m}$. 

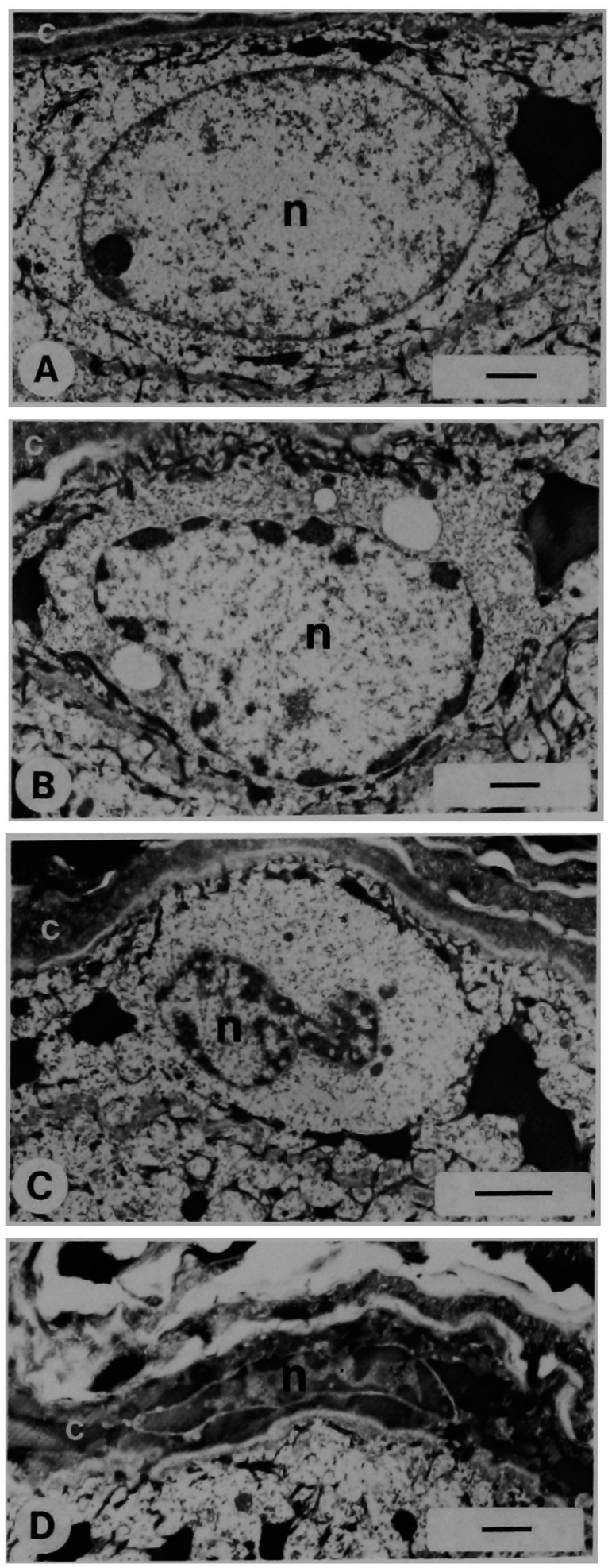

Fig. 4. Disintegration of the nucleus. Samples of epidermis were obtained from fetal animals on day 20 of gestation. Nuclei (n) of the cells located in the outermost area of s. granulosum were displayed. A white $\mathrm{c}$ denotes the s. corneum. Bars $=1 \mu \mathrm{m}(\mathbf{A}, \mathbf{B}, \mathbf{D})$, $2 \mu \mathrm{m}$ (C). positive staining was seen in the nuclei of the cells located between the s. spinosum and the s. granulosum as well as in the area of inner root sheath of developing hair follicles. As described in the previous section, the nuclei in the cells of s. spinosum showed no conspicuous apoptotic structures, while the results suggest that they began to undergo the DNA fragmentation. It confirms the results reported earlier [29]. We speculate that some cells in s. germinativum preparing to form hair follicles may undergo DNA fragmentation, since internal and external root sheath cells or their progenitors were stained distinctly (Fig. 6A, B). The staining in the s. corneum seemed to be an artifact, since it could be seen in a control experiment as well (Fig. 6C).

\section{Autophagy and lysosome}

Autophagy is one of the non-apoptotic physiological degradation systems in the cell. Some cells in the $\mathbf{s .}$ granulosum were rich in lysosomes (Fig. 7A). The cristae structure of mitochondria, which may be destroyed within 10 min [12], was observed in the oval boxes in Fig. 7B, and probably also in $7 \mathrm{C}$, suggesting macroautophagy of mitochondria.

Antibodies against cathepsin B, D and a lysosomeendosome specific glycoprotein were used to study the distribution of lysosomes in the tissue. The results of western blotting are shown in Fig. 8. Both lane 4 (cathepsin D) and lane 5 (cathepsin B) represented two bands, which are thought to correspond with the single chain form and the heavy chain of the two chain form [8, 27]. Essentially non-specific bands were not seen. The antibody against lgp120 appeared to react solely with two antigens of which sizes are around $60 \mathrm{kD}$ (lane 3). It was an epidermis-specific phenomenon.

All three markers of lysosomes exhibited similar patterns. That is, the s. spinosum and the s. granulosum were positively stained whereas the s. germinativum and the $s$. corneum were not stained. The whole area of the $s$. spinosum and the s. granulosum was evenly stained except for the boundary area between $s$. granulosum and $s$. cornium and inside of the PNC (Fig. 9C-H). Vimentin was detected only in the dermis (Fig. 9B), supporting the reliability of the assay. Our results on the localization of lysosomal markers are largely consistent with those of Hara et al [14].

\section{Discussion}

Although one of the most prominent morphological markers of apoptosis is a change in the nucleus, it is not so easy to capture the process of nuclear disintegration in keratinocytes probably due to the rapid progress of disintegration in contrast to the relatively long life span of the cells. Odland [30] showed one photograph of a degenerating nucleus, but a detailed presentation has not been done. Neonatal (and also day 20 fetal) epidermis showed a high proportion of cells with degenerating nuclei around 

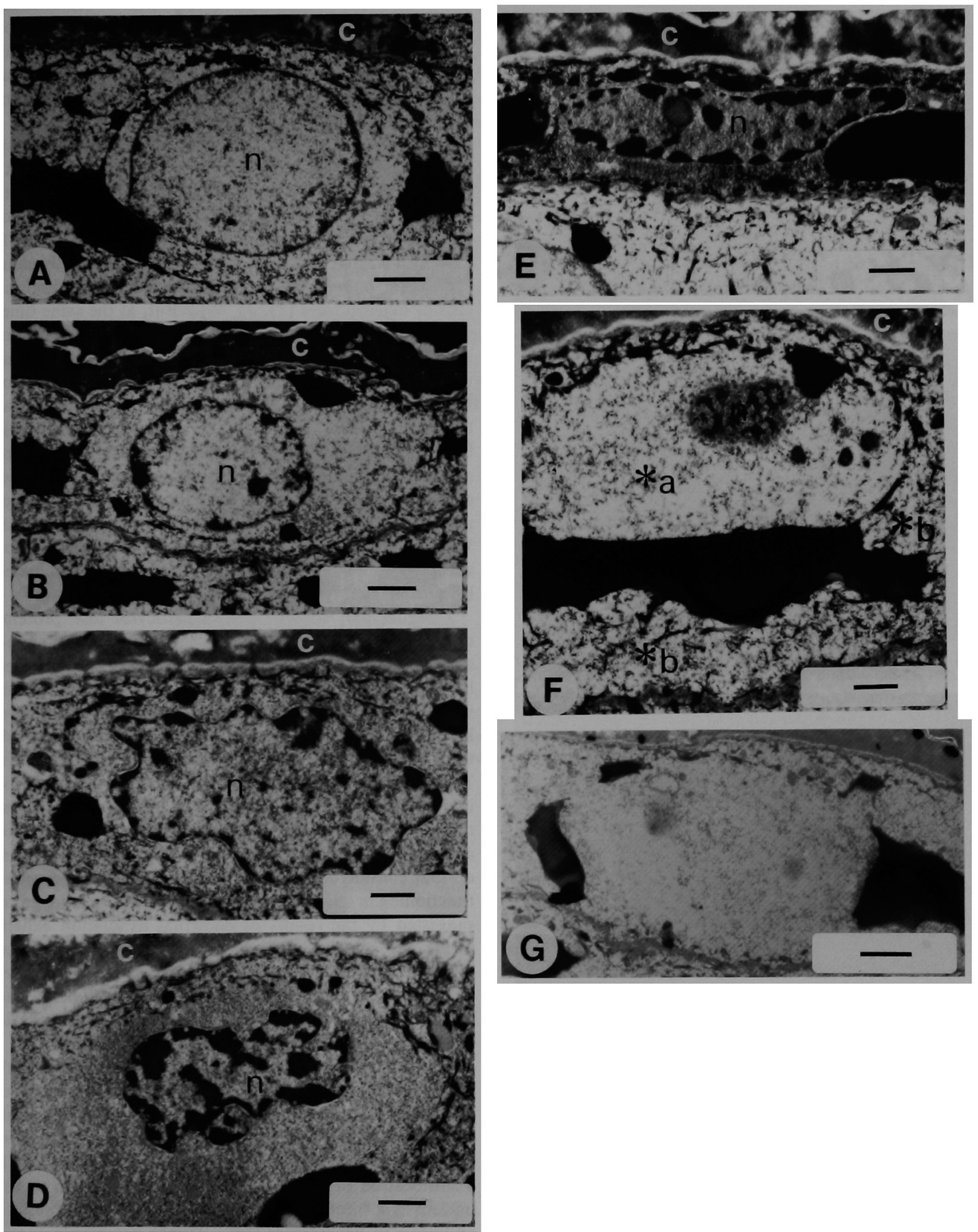

Fig. 5. Disintegration of the nucleus. Samples of epidermis were obtained from neonatal animals on the day of birth. Bars $=2 \mu \mathrm{m}(\mathbf{A}, \mathbf{B})$, $1 \mu \mathrm{m}$ (C-G). Cytoplasm: inside ( $\left.{ }^{*} a\right)$ and outside $\left({ }^{*} b\right)$ of PNC. n, nucleus. A white $c$ denotes the s. corneum. 

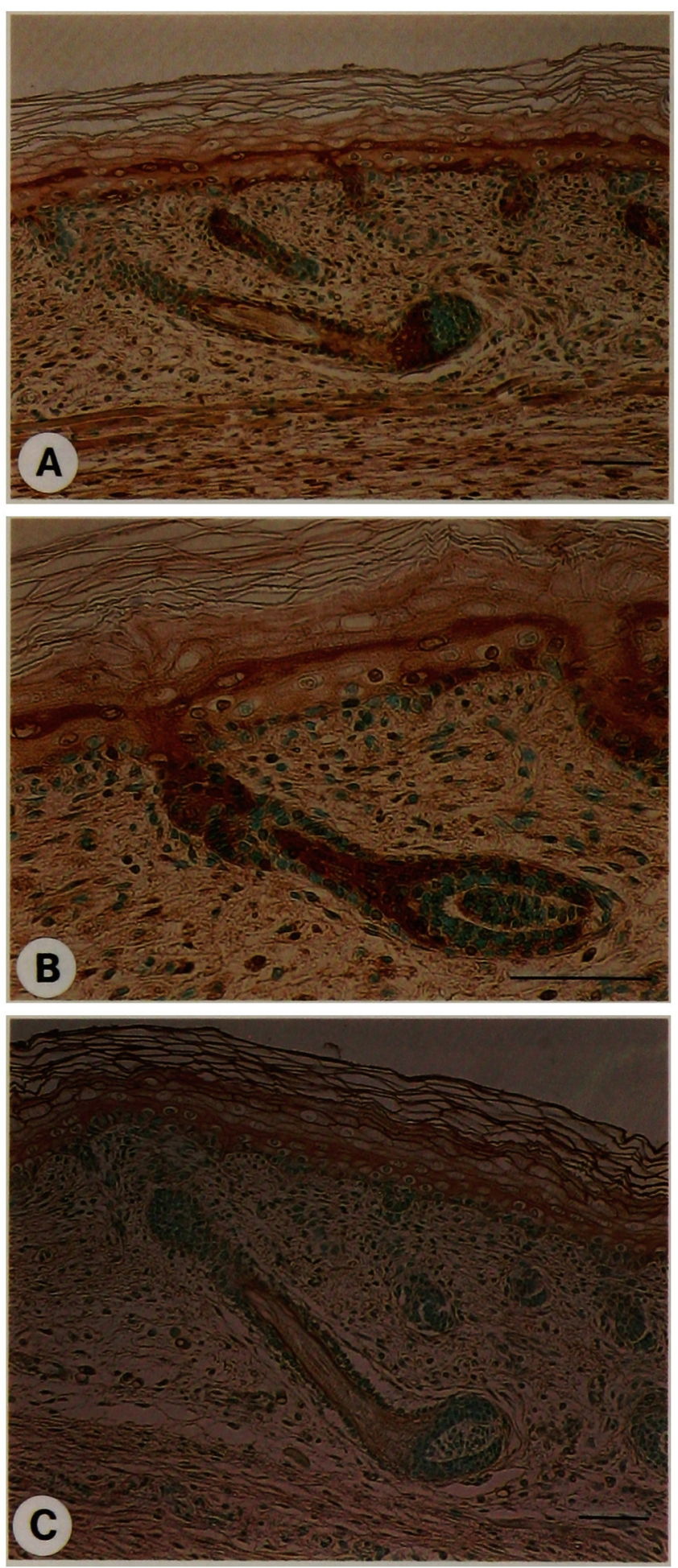

Fig. 6. In situ end-labeling of DNA strand breaks. (A, B) DNA fragmentation is evident as brown color. Nuclei were counterstained with methylgreen-pyronine. Details of the methods are provided in the text. (C) Control experiment. Terminal deoxynucleotidyl transferase was not included in the reaction mixture. Samples of epidermis were obtained from neonatal animals on the day of birth. Bars $=50 \mu \mathrm{m}$. the border between the s. granulosum and the s. corneum. This is probably due to the relatively short life-span of the keratinocytes as compared to the rate of the transition from the s. granulosum to the s. corneum. Thus, examination of the epidermis of the neonatal animals enabled us to explore the features of degenerating nuclei in various stages systematically.

PCD has been shown to occur in the morphogenesis of multicellular organisms [6, 18]. Most and possibly all forms of cell death including PCD in higher animals are proposed to be classified into one of two distinct morphological patterns, that is, apoptosis or necrosis [52]. PCD occurs in most cases by apoptosis so that cells become "apoptotic bodies" to be phagocytosed by neighboring cells or macrophages $[23,35,49]$. But, at the same time, some types of cells such as erythrocytes [28] or keratinocytes do not form apoptotic bodies and these cells continue to function for several days or weeks after the execution of semi-apoptotic nuclear degeneration accompanied by the loss of organelles. Especially, keratinocytes appear to die by a genuine suicide mechanism. Even in the case of anuran metamorphosis, a significant number of epidermal cells die without the aid of neighboring cells or macrophages [21]. These observations raise some questions: What is the role of the degradation of organelles by autophagy? Is the life of the cell prolonged or terminated by autophagy?

Seglen [40] showed that hepatocytes lose proteins through autophagy and die in a medium depleted of amino acids whereas they survive when autophagy is suppressed by 3-methyladenine. Jia et al. [19] showed that TNF- $\alpha$ induced DNA fragmentation and cytolysis were completely inhibited by the addition of 3-methyladenine to the culture medium in the case of T-lymphoblastic leukemic cells. Toxin-induced apoptotic cell lysis was also found to be inhibited by 3-methyladenine [37]. These results suggest that autophagy is required for execution of cell death or apoptosis at least in some situations. In contrast, Piao et al. [32] considered autophagy to be one of the processes functioning in self-protection against radiation damage, as suggested by the results of sublethal irradiation experiments on splenic lymphocytes. During the terminal differentiation of epidermal cells as well as erythrocytes [28], almost all organelles disappear before cell death and this is far from the classical definition of apoptosis in which there are very few changes in the organelles.

Several papers, which introduce new concepts with regard to the relationship between lysosomal enzymes and $\mathrm{PCD} /$ apoptosis, have recently been published. High levels of expression of cathepsin D antisense RNA have been shown to protect HeLa cells from induced PCD [7]. Translocation of cathepsin B from the cytoplasm to the nucleus is a mechanism contributing to bile salt-induced apoptosis of hepatocytes [34]. Tumor necrosis factor $\alpha$ induced apoptosis was found to be completely inhibited by inhibition of autophagy [19]. Caspase-3-like protease was shown to be activated by lysosome proteases [16]. These 

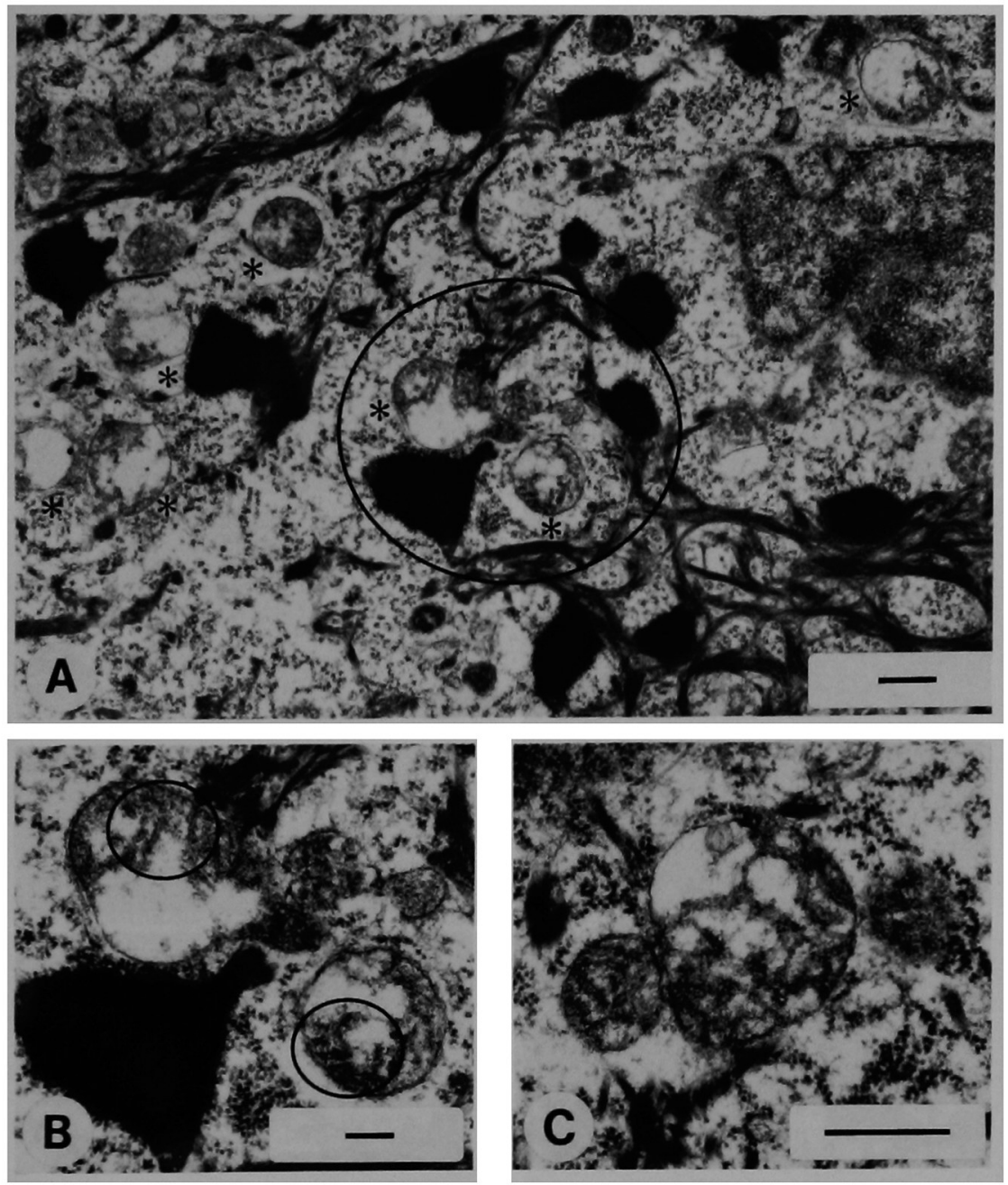

Fig. 7. Lysosomes in cells of the s. granulosum of fetal animals at day 20 of gestation. (A) Asterisks denote lysosomes. Lysosome in the oval box in (A) and that in the other area are shown in (B) and (C), respectively. Bars $=500 \mathrm{~nm}(\mathbf{A}), 200 \mathrm{~nm}(B, C)$.

\section{$\begin{array}{lllll}1 & 2 & 3 & 4 & 5\end{array}$}

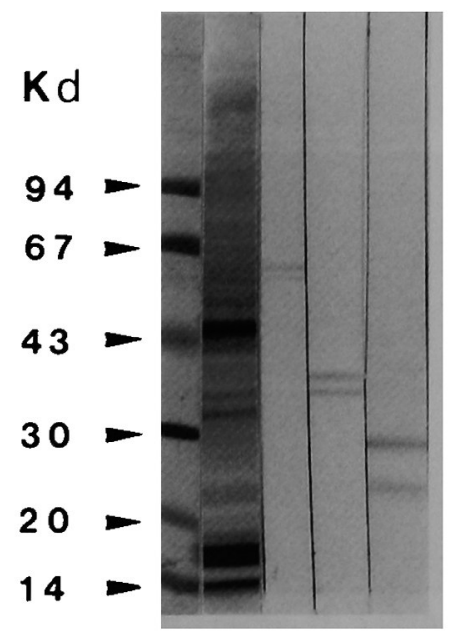

Fig. 8. Western blot analysis of a skin homogenate prepared from neonatal animals on the day of birth. Proteins were reacted with anti-lgp 120 antibody (lane 3), anti-cathepsin D antibody (lane 4), and anti-cathepsin B antibody (lane 5). Patterns of marker proteins and amido black staining are shown in lane 1 and lane 2, respectively. findings seem to suggest that apoptosis is induced by cathepsins, however, the mechanisms involved may not be so simple. In mice deficient in cathepsin $\mathrm{D}$, cells in the intestinal mucosa and lymphoid cells have been found to undergo severe cell death [36]. In apoptosis of PC12 cells following serum deprivation, cathepsin $\mathrm{D}$ acts as a death mediator and this death-inducing activity of cathepsin D was found to be prevented by cathepsin B [42]. The results obtained so far may cause some confusion, however, we think that there is convincing evidence of a close relationship between lysosomal proteases and $\mathrm{PCD} /$ apoptosis. It is also intriguing that a human apoptosis specific protein was found to have homology with the product of APG 5 [13], a gene involved in autophagy in yeast [47].

Recently van Leyen et al. [48] used the term "programmed organelle degradation" and suggested that 15-lipoxygenase plays an important role in destroying membrane-enclosed organelles in concert with cytoplasmic proteases in reticulocytes, central fiber cells of the eye lens, 

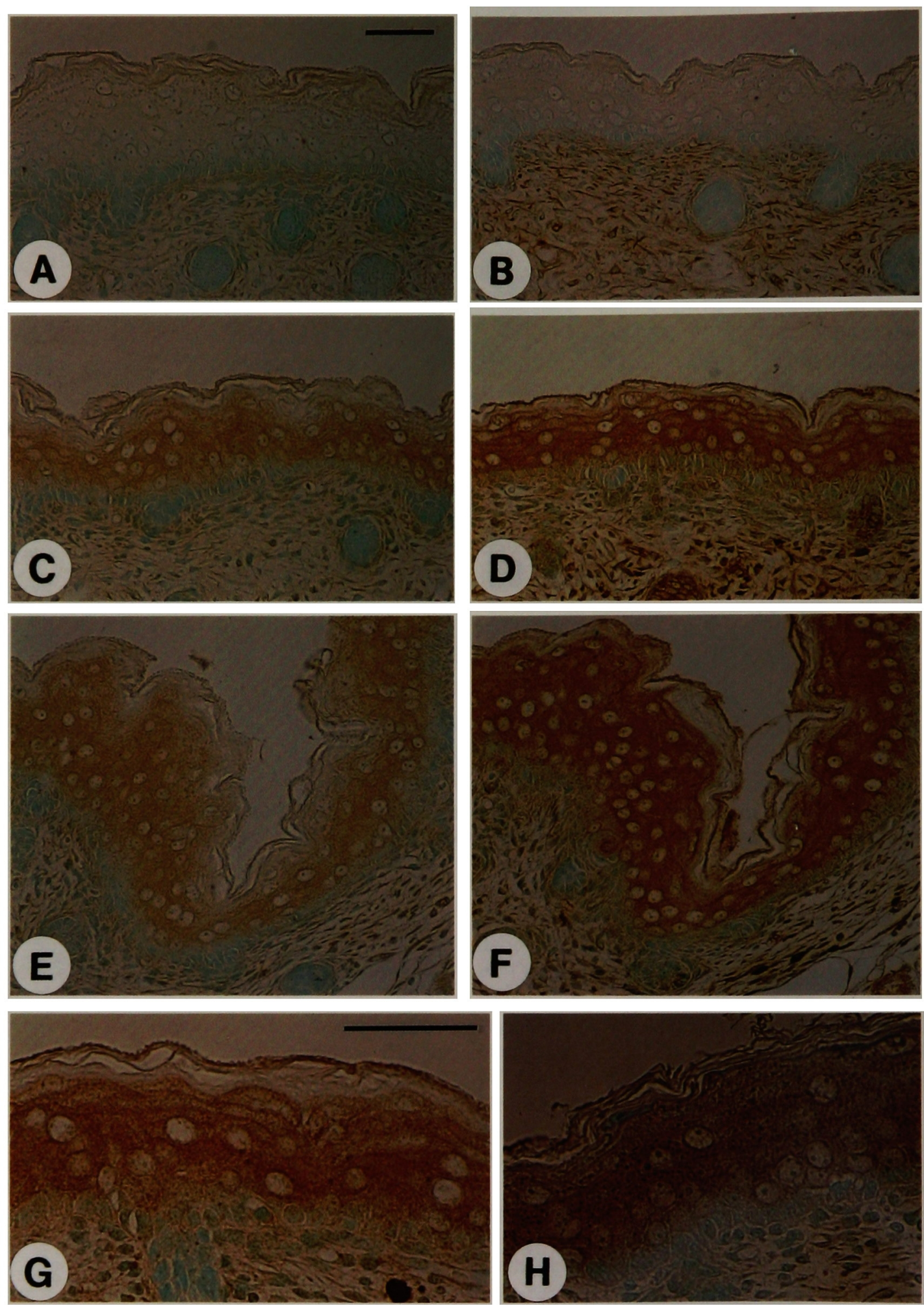

Fig. 9. Immunohistochemical staining of skin sections prepared from a neonatal animal on the day of birth. (A) Control experiment without primary antibody-treatment. Other sections were treated with anti-vimentin antibody (B), anti-cathepsin D antibody (C, E), anti-cathepsin B antibody $(\mathbf{D}, \mathbf{F}, \mathbf{G})$, and anti-lgp120 antibody $(\mathbf{H})$. The bar $(50 \mu \mathrm{m})$ in $(\mathbf{A})$ is applicable to $(\mathbf{A})-(\mathbf{F})$. The bar $(50 \mu \mathrm{m})$ in $(\mathbf{G})$ is also applicable to $(\mathbf{H})$. 
and keratinocytes. Several investigators have studied the localization of lysosomal proteases in the skin. Cathepsin $E$ was shown to be distributed through all epidermal cells obtained from both rat and human skin samples, whereas cathepsin D appeared in cells of the s. granulosum [14]. Sato et al. [38] showed that the cathepsin B and C immunoreactivity was prominent in the lower s. spinosum and the s. germinativum, whereas cathepsin L and D immunoreactivity was intense in the upper s. spinosum and the $s$. granulosum of the rat. In contrast, cathepsin $L$ and B antibodies was shown to be immunoreacted as diffuse staining in the entire epidermis of normal human skin [20]. In the present study, we investigated the localization of cathepsins in fetal rat epidermis using carefully selected antibodies, compared to the distributions of apoptotic/preapoptotic and nonapoptotic sites in the same tissue.

Lens cell differentiation may be similar, but is an extreme case. During development, lens cells became transparent because of the degradation of nuclei and other organelles at least in part [2]. The cells that have lost their nuclei and organelles are maintained for the entire life of the organisms. Thus the modes of cell death are diverse and tissue specific. When organisms need to keep some terminally differentiated cells alive for several hours, days, weeks, months, or years, different mechanisms may be operative in each case.

\section{Acknowledgments}

The authers express gratitude to Dr. Shigenobu Toné for helpful discussions.

\section{References}

1. Aravind, L., Dixit, V. M. and Koonin, E. V.: The domains of death: evolution of apoptosis machinery. TIBS 24; 47-53, 1999.

2. Bassnett, S. and Mataic, D.: Chromatin degradation in differentiating fiber cells of the eye lens. J. Cell Biol. 137; 3749, 1997.

3. Bonneville, M.A.: Observations on epidermal differentiation in the fetal rat. Am. J. Anat. 123; 147-164, 1968.

4. Cai, J., Yang, J. and Jones, D. P.: Mitochondrial control of apoptosis: the role of cytochrome c. Biochim. Biophys. Acta 1366; 139-149, 1998.

5. Clarke, P. G. H.: Developmental cell death: morphological diversity and multiple mechanisms. Anat. Embryol. 181; 195213, 1990.

6. Clarke, P. G. H. and Clarke, S.: Nineteenth century research on naturally occurring cell death and related phenomena. Anat. Embryol. 193; 81-99, 1996.

7. Deiss, L. P., Galinka, H., Berissi, H., Cohen, O. and Kimchi, A.: Cathepsin D protease mediates programmed cell death induced by interferon- $\gamma$, Fas/APO-1 and TNF- $\alpha$. EMBO J. 15; 3861-3870, 1996.

8. Fujita, H., Tanaka, Y., Noguchi, Y., Kono, A., Himeno, M. and Kato, K.: Isolation and sequencing of a cDNA clone encoding rat liver lysosomal cathepsin $\mathrm{D}$ and the structure of three forms of mature enzymes. Biochem. Biophys. Res. Commun. 179; 190-196, 1991.

9. Fusenig, N. E., Limat, A., Stark, H. J. and Breitkreutz, D.: Modulation of the differentiated phenotype of keratinocytes of the hair follicle and from epidermis. J. Dermatol. Sci. 7 (Suppl); S142-151, 1994.

10. Gavrieli, Y., Sherman, Y. and Ben-Sasson, S. A.: Identification of programmed cell death in situ via specific labeling of nuclear DNA fragmentation. J. Cell Biol. 119; 493-501, 1992.

11. Gibbs, S., Boelsma, E., Kempenaar, J. and Ponec, M.: Temperature-sensitive regulation of epidermal morphogenesis and the expression of cornified envelope precursors by EGF and TGF alpha. Cell Tissue Res. 292; 107-114, 1998.

12. Glaumann, H., Berezesky, I. K., Ericsson, J. L. E. and Trump, B. F.: Lysosomal degradation of cell organelles I. Ultrastructural analysis of uptake and digestion of intravenously injected mitochondria by Kupffer cells. Lab. Invest. 33; 239-251, 1975.

13. Hammond, E. M., Brunet, C. L., Johnson, G. D., Parkhill, J., Milner, A. E., Brady, G., Gregory, C. D. and Grand, R. J. A.: Homology between a human apoptosis specific protein and the product of $A P G 5$, a gene involved in autophagy in yeast. $F E B S$ Letters 425; 391-395, 1998.

14. Hara, K., Fukuyama, K., Sakai, H., Yamamoto, K. and Epstein, W. L.: Purification and immunohistochemical localization of aspartic proteinases in rat epidermis. $J$. Invest. Dermatol. 100; 394-399, 1993.

15. Ihara, S., Watanabe, M., Nagao, E. and Shioya, N.: Formation of hair follicles from a single-cell suspension of embryonic rat skin by a two-step procedure in vitro. Cell Tissue Res. 266; 65-73, 1991.

16. Ishisaka, R., Utsumi, T., Yabuki, M., Kanno, T., Furuno, T., Inoue, $M$. and Utsumi, K.: Activation of caspase-3-like protease by digitonin-treated lysosomes. FEBS Letters 435; 233 236, 1998.

17. Ito, Y. and Ohtsuki, Y.: Localization of apoptotic cells in the human epidermis by an in situ DNA nick end-labeling method using confocal reflectant laser microscopy. J. Histochem. Cytochem. 46; 783-786, 1998.

18. Jacobson, M. D., Weil, M. and Raff, M. C.: Programmed cell death in animal development. Cell 88; 347-354, 1997.

19. Jia, L., Dourmashkin, R. R., Allen, P. D., Gray, A. B., Newland, A. C. and Kelsey, S. M.: Inhibition of autophagy abrogates tumor necrosis factor $\alpha$ induced apoptosis in human T-lymphoblastic leukemia cells. Brit. J. Haematol. 98; 673$685,1997$.

20. Kawada, A., Hara, K., Kominami, E., Hiruma, M., Noguchi, H. and Ishibashi, A.: Processing of cathepsin L, B and D in psoriatic epidermis. Arch. Dermatol. Res. 289; 87-93, 1997.

21. Kinoshita, T., Sasaki, F. and Watanabe, K.: Autolysis and heterolysis of the epidermal cells in anuran tadpole tail regression. J. Morphol. 185; 269-275, 1985.

22. Kominami, E., Tsukahara, T., Bando, Y. and Katsunuma, N.: Distribution of cathepsin $\mathrm{B}$ and $\mathrm{H}$ in rat tissues and peripheral blood cells. J. Biochem. 98; 87-93, 1985.

23. Lang, R. A. and Bishop, J. M.: Macrophages are required for cell death and tissue remodeling in the developing mouse eye. Cell 74; 453-462, 1993.

24. Lewis, V., Green, S. A., Marsh, M., Vihko, P., Helenius, A. and Mellman, I.: Glycoproteins of the lysosomal membrane. J. Cell Biol. 100; 1839-1847, 1985.

25. McCall, C. A. and Cohen, J. J.: Programmed cell death in terminally differentiating keratinocytes: Role of endogenous endonuclease. J. Invest. Dermatol. 97; 111-114, 1991.

26. Miyachi, Y., Yoshimura, N., Suzuki, S., Hamakubo, T., Kanagi, R., Imamura, S. and Murachi, T.: Biochemical demonstration and immunohistochemical localization of cal- 
pain in human skin. J. Invest. Dermatol. 86; 346-349, 1986.

27. Moin, K., Day, N. A., Sameni, M., Hasnain, S., Hirama, T. and Sloane, B. F.: Human tumor cathepsin B. Comparison with normal liver cathepsin B. Biochem. J. 285; 427-434, 1992.

28. Morioka, K., Tone, S., Mukaida, M. and Takano-Ohmuro, H.: The apoptotic and nonapoptotic nature of the terminal differentiation of erythroid cells. Exp. Cell Res. 240; 206-217, 1998.

29. Nakamura, K., Ito, Y., Matsumoto, K., Daikoku, E., Kiyokane, K. and Otsuki, K.: The relationship between apoptosis and keratinization in human epidermis. Acta Histochem. Cytochem. 32; 77-83, 1999.

30. Odland, G. F.: Histology and fine structure of epidermis. In "The Skin," ed. by E. B. Helwig and F. K. Mostofi, Williams and Wilkins, Baltimore, 1971, pp. 28-46.

31. Odland, G. F. and Reed, T. H.: Epidermis. In "Ultrastructure of Normal and Abnormal Skin," ed. by A.S. Zelickson, Lea \& Febiger, Philadelphia, 1967, pp. 54-75.

32. Piao, Y-J., Liu, L-P., Huang, X-X., Huo, X., Qiao, D-F. and An, L-B.: Radiation-induced autophagic apoptosis of rat splenic lymphocytes. Acta Histochem. Cytochem. 30; 629-636, 1997.

33. Rhodin, J. A. G.: Skin and appendages. Histology: A Text and Atlas, Oxford University Press, New York, Oxford, 1974, pp. 476-500.

34. Roberts, L. R., Kurosawa, H., Bronk, S. F., Fesmier, P. J., Agellon, L. B., Leung, W.Y., Mao, F. and Gores, G. J.: Cathepsin B contributes to bile salt-induced apoptosis of rat hepatocytes. Gastroenterology 113; 1714-1726, 1997.

35. Robertson, A.M. G. and Thomson, J. N.: Morphology of programmed cell death in the ventral nerve cord of Caenorhabditis elegans larvae. J. Embryol. Exp. Morphol. 67; 89-100, 1982.

36. Saftig, P., Hetman, M., Schmahl, W., Weber, K., Heine, L., Mossmann, H., Koster, A., Hess, B., Evers, M., von Figra, K. and Peters, C.: Mice deficient for the lysosomal proteinase cathepsin D exhibit progressive atrophy of the intestinal mucosa and profound destruction of lymphoid cells. EMBO J. 14; 3599-3608, 1995.

37. Sandvig, K. and van Deurs, B.: Toxin-induced cell lysis: Protection by 3 - the intestinal mucosa and profound destruction of lymphoid tissue. methyladenine and cycloheximide. Exp. Cell Res. 200; 253-262, 1992.

38. Sato, K., Waguri, S., Ohsawa, Y., Nitatori, T., Kon, S., Kominami, E., Watanabe, T., Gotow, T. and Uchiyama, Y.: Immunocytochemical localization of lysosomal cysteine and aspartic proteinases, and ubiquitin in rat epidermis. Arch. Histol. Cytol. 60; 275-287, 1997.
39. Schweichel, J. U. and Merker, H. J.: The morphology of various types of cell death in prenatal tissues. Teratology 7; 253-266, 1973.

40. Seglen, P. O.: DNA ploidy and autophagic protein degradation as determinants of hepatocellular growth and survival. Cell Biol. Toxicol. 13; 301-315, 1997.

41. Sengel, P.: Morphogenesis of skin. In "Developmental and Cell Biology Series," ed. by M. Abercrombie, D. R. Newth and J. G. Torrey, Cambridge University Press, Cambridge, 1976, pp. 1-17.

42. Shibata, M., Kanamori, S., Isahara, K., Ohsawa, Y., Konishi, A., Kametaka, S., Watanabe, T., Ebisu, S., Ishido, K., Kominami, E. and Uchiyama, Y.: Participation of cathepsin B and $\mathrm{D}$ in apoptosis of $\mathrm{PC} 12$ cells following serum deprivation. Biochem. Biophys. Res. Commun. 251; 199-203, 1998.

43. Smack, D. P., Korge, B. P. and James, W. D.: Keratin and keratinization. J. Am. Acad. Dermatol. 30; 85-102, 1994.

44. Susin, S. A., Lorenzo, H. K., Zamzami, N., Marzo, I., Snow, B. E., Brothers, G. M., Mangion, J., Jacotot, E., Costantini, P., Loeffler, M., Larochette, N., Goodlett, D. R., Aebersold, R., Siderovski, D. P., Penninger, J.M. and Kroemer, G.: Molecular characterization of mitochondrial apoptosis-inducing factor. Nature 397; 441-446, 1999.

45. Suzuki, H., Fukuyama, K. and Epstein, W. L.: Changes in nuclear DNA and RNA during epidermal keratinization. Cell Tissue Res. 184; 155-167, 1977.

46. Takano-Ohmuro, H., Mukaida, M. and Morioka, K.: Distribution of actin, myosin, and spectrin during enucleation in erythroid cells of hamster embryo. Cell Motil. Cytoskel. 34; 95-107, 1996.

47. Tsukada, M. and Ohsumi, Y.: Isolation and characterization of autophagy-defective mutants of Saccharomyces cerevisiae. FEBS Letters 333; 169-174, 1993.

48. van Leyen, K., Duvoisin, R. M., Engelhardt, H. and Wiedmann, M.: A function for lipoxygenase in programmed organelle degradation. Nature 395; 392-395, 1998.

49. Watanabe, K. and Sasaki, F.: Ultrastructural changes in the tail muscles of anuran tadpoles during metamorphosis. Cell Tissue Res. 155; 321-336, 1974.

50. Wier, K. A., Fukuyama, K. and Epstein, W. L.: Nuclear changes during keratinization of normal human epidermis. $J$. Ultrastruct. Res. 37; 138-145, 1971.

51. Wyllie, A. H.: Glucocorticoid-induced thymocyte apoptosis is associated with endogenous endonuclease activation. Nature 284; 555-556, 1980.

52. Wyllie, A. H., Kerr, J.F. R. and Currie, A. R.: Cell death: The significance of apoptosis. Int. Rev. Cytol. 68; 251-306, 1980. 